6. Wölfel R, Corman VM, Guggemos W, Seilmaier M, Zange S, Müller MA, et al. Virological assessment of hospitalized patients with COVID-2019. Nature. 2020;581:465-9. https:/ / doi.org/10.1038/s41586-020-2196-x

7. Jones TC, Mühlemann B, Veith T, Zuchowski M, Hofmann J, Stein A, et al. An analysis of SARS-CoV-2 viral load by patient age [cited 2020 May 3]. https:/ / zoonosen. charite.de/fileadmin/user_upload/microsites/m_cc05/ virologie-ccm/dateien_upload/Weitere_Dateien/ analysis-of-SARS-CoV-2-viral-load-by-patient-age.pdf

8. Stringhini S, Wisniak A, Piumatti G, Azman AS, Lauer SA, Baysson $\mathrm{H}$, et al. Seroprevalence of anti-SARS-CoV-2 IgG antibodies in Geneva, Switzerland (SEROCoV-POP): a population-based study. Lancet. 2020 Jun 11 [Epub ahead of print]. https:/ / doi.org/10.1016/S0140-6736(20)31304-0

Address for correspondence: Isabella Eckerle, Laboratory of Virology and Geneva Centre for Emerging Viral Diseases, Geneva University Hospitals and Faculty of Medicine, University of Geneva, 4 Rue Gabrielle-Perret-Gentil, 1211 Geneva 14, Switzerland; email: isabella.eckerle@hcuge.ch

\section{Viral RNA Load in Mildly Symptomatic and Asymptomatic Children with COVID-19, Seoul, South Korea}

\author{
Mi Seon Han, ${ }^{1}$ Moon-Woo Seong, ${ }^{1}$ Namhee Kim, \\ Sue Shin, Sung Im Cho, Hyunwoong Park, \\ Taek Soo Kim, Sung Sup Park, Eun Hwa Choi
}

\begin{abstract}
Author affiliations: Seoul Metropolitan Government-Seoul National University Boramae Medical Center, Seoul, South Korea (M.S. Han, N. Kim, S. Shin, H. Park); Seoul National University College of Medicine, Seoul (M.-W. Seong, S. Shin, H. Park, T.S. Kim, S.S. Park, E.H. Choi); Seoul National University Hospital, Seoul (M.-W. Seong, S.I. Cho, T.S. Kim, S.S. Park); Seoul National University Children's Hospital, Seoul (E.H. Choi)
\end{abstract}

DOI: https://doi.org/10.3201/eid2610.202449

Along with positive SARS-CoV-2 RNA in nasopharyngeal swabs, viral RNA was detectable at high concentration for $>3$ weeks in fecal samples from 12 mildly symptomatic and asymptomatic children with COVID-19 in Seoul, South Korea. Saliva also tested positive during the early phase of infection. If proven infectious, feces and saliva could serve as transmission sources.
Tn the current pandemic of coronavirus disease I(COVID-19), detecting severe acute respiratory syndrome coronavirus 2 (SARS-CoV-2) in children suspected of having the disease is essential for both infection control and establishing a definite causal relationship in unprecedented cases $(1,2)$. However, efforts are hindered by negative SARS-CoV-2 test results for respiratory specimens and possible cross-reactivity with other coronaviruses among seropositive cases $(2,3)$. Little is known about the value of various samples other than nasopharyngeal or oropharyngeal swab specimens in diagnosing COVID-19 and understanding the viral dynamics of SARS-CoV-2 in children. Virus RNA was persistently detected in rectal swab specimens in a previous study, although the infectiousness of the virus is unknown (4). We analyzed the viral RNA load kinetics of SARS-CoV-2 in various clinical specimens in children with COVID-19.

In South Korea, all confirmed case-patients, regardless of disease severity, must be isolated in hospitals or isolation facilities. For this study, we included all children $<18$ years of age who were confirmed to have COVID-19 by positive results for SARS-CoV-2 in combined nasopharyngeal and oropharyngeal swab specimens and who were hospitalized in Seoul Metropolitan Government-Seoul National University Boramae Medical Center during March 8-April 28,2020 . We extracted RNA from clinical specimens and detected SARS-CoV-2 by using the Allplex 2019nCoV Assay kit (Seegene, http:/ / www.seegene.com). We performed quantitation of the viral RNA with a standard curve constructed using in vitro transcribed RNA. This study was approved by the institutional review board at SMG-SNU Boramae Medical Center; written consent was waived.

We included 12 children in the study; 9 were mildly symptomatic and 3 were asymptomatic (Appendix Table 1, https://wwwnc.cdc.gov/EID/ article/26/10/20-2449-App1.pdf). Median age was 6.5 years (range 27 days -16 years). Nasopharyngeal swab specimens tested positive for SARS-CoV-2 RNA in all 12 children, and 11 (92\%) had positive RNA in their fecal specimens (Appendix Table 2). We collected saliva samples from 11 children; 8 (73\%) tested positive.

Viral RNA load in the nasopharyngeal swabs peaked early at median 7.56 (range 6.19-10.56) $\log _{10}$ copies $/ \mathrm{mL}$ and decreased over time ( $\mathrm{p}<0.001$ for trend) (Figure, panel A). The positivity of the specimens was 75\% during week 2 and 55\% during week 3 (Appendix Table 2). In comparison, the median initial fecal RNA load was 7.68 (range $<4.10-10.27$ ) $\log _{10}$ copies/mL and

\footnotetext{
${ }^{1}$ These authors contributed equally to this article.
} 

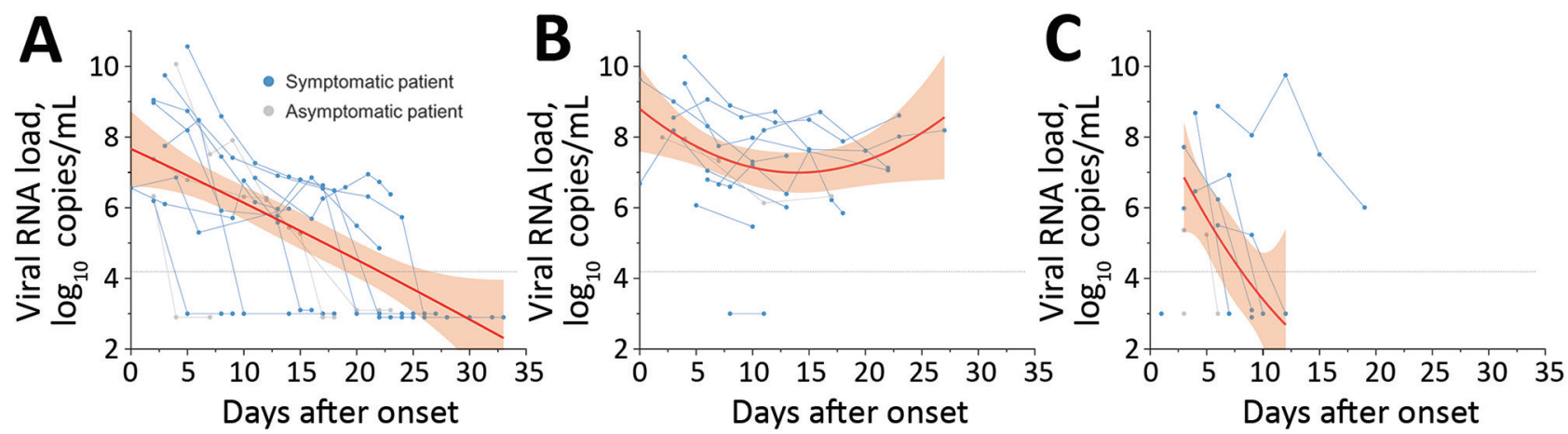

Figure. Changes in severe acute respiratory syndrome coronavirus 2 viral RNA load in A) nasopharyngeal swabs, B) feces, and C) saliva of mildly symptomatic and asymptomatic children with coronavirus disease over time, South Korea. The thick red line indicates trend in viral RNA load over time, and the shaded areas represent $95 \% \mathrm{Cls}$. The dashed line indicates the detection limit $\left(1.25 \times 10^{4}\right.$ copies $/ \mathrm{mL}$ ). Specimens with undetectable viral RNA loads are shown under the dashed line. Days after onset indicates days after symptom onset for symptomatic patients, days after diagnosis for asymptomatic patients.

remained steadily high $(\mathrm{p}=0.148$ for trend $)$ for $>3$ weeks (Figure, panel B). Fecal positivity remained $\geq 80 \%$. The median RNA load in fecal samples was significantly higher than that for nasopharyngeal swab specimens during week 2 (7.26 vs. $6.19 \log _{10}$ copies $/ \mathrm{mL} ; \mathrm{p}=0.006$ ) and week 3 (7.61 versus $5.49 \log _{10}$ copies $\left./ \mathrm{mL} ; \mathrm{p}=0.006\right)$. Except for 1 case, the RNA load in saliva declined rapidly with time ( $p=0.003$ for trend) (Figure, panel C). Positivity in saliva samples was $80 \%$ in week 1 but dropped sharply to $33 \%$ in week 2 and $11 \%$ in week 3 .

We collected urine specimens from the 12 patients after a median of 3 (range $0-8$ ) days and plasma specimens at 2 (range $0-8$ ) days from onset. Of these, urine samples of $2(17 \%)$ patients tested positive (median load 5.69 [range 3.82-7.55] $\log _{10}$ copies/ $\mathrm{mL})$. Only 1 (8\%) patient, 27 days of age, had RNA detected in plasma.

Symptomatic children had higher initial RNA load in nasopharyngeal swab specimens than asymptomatic children (9.01 vs. $6.32 \log _{10}$ copies $/ \mathrm{mL} ; \mathrm{p}=0.048$ ). We observed no significant differences in feces and in saliva and no correlation between RNA load and age.

In this study, we detected SARS-CoV-2 RNA in feces of $92 \%$ of mildly ill or asymptomatic children with COVID-19. In addition, the RNA load in feces remained steadily high, whereas that in nasopharyngeal swab specimens and saliva declined with time in both symptomatic and asymptomatic children. The detection of SARS-CoV-2 RNA in feces does not necessarily mean that infectious virus is present; thus, lack of virus isolation in our study limits interpretation in the context of infectivity. However, viable virus was isolated in feces in previous studies, and infectivity was dependent on viral RNA load $(3,5,6)$. Considering these findings, proper handwashing when changing diapers in infants and adequate hygiene measures in restrooms are recommended to prevent the potential spread of the virus among household contacts.

Our findings also suggest that feces is a promising and reliable source for detecting both current and recent SARS-CoV-2 infection because the viral RNA is present in high loads for a prolonged time. Fecal specimens could aid in seeking the etiologic relationship between COVID-19 and unexpected manifestations in children.

We also detected SARS-CoV-2 RNA in saliva during the early phase of the infection for a short period of time. Live virus was isolated in saliva in a previous study, and the possibility of airborne transmission of the virus through normal speaking has been raised $(7,8)$. Although the viral load in saliva drops rapidly, our findings suggest the necessity for children to wear masks, especially in schools, where children would talk in close proximity.

\section{About the Author}

Dr. Han is a clinical assistant professor in the Division of Pediatric Infectious Diseases, Department of Pediatrics at Seoul Metropolitan GovernmentSeoul National University Boramae Medical Center, Seoul, South Korea. Her research interests include respiratory virus infections and infectious diseases in immunocompromised hosts.

\section{References}

1. Riphagen S, Gomez X, Gonzalez-Martinez C, Wilkinson N, Theocharis P. Hyperinflammatory shock in children during COVID-19 pandemic. Lancet. 2020;395:1607-8. https:/ / doi.org/10.1016/S0140-6736(20)31094-1

2. Verdoni L, Mazza A, Gervasoni A, Martelli L, Ruggeri M, Ciuffreda M, et al. An outbreak of severe Kawasaki-like 
disease at the Italian epicentre of the SARS-CoV-2 epidemic: an observational cohort study. Lancet. 2020 May 13 [Epub ahead of print]. https:// doi.org/10.1016/S01406736(20)31103-X

3. Wölfel R, Corman VM, Guggemos W, Seilmaier M, Zange S, Müller MA, et al. Virological assessment of hospitalized patients with COVID-2019. Nature. 2020;581:465-9. https://doi.org/10.1038/ s41586-020-2196-X

4. Xu Y, Li X, Zhu B, Liang H, Fang C, Gong Y, et al. Characteristics of pediatric SARS-CoV-2 infection and potential evidence for persistent fecal viral shedding. Nat Med. 2020;26:502-5. https:/ / doi.org/10.1038/s41591-020-0817-4

5. Xiao F, Sun J, Xu Y, Li F, Huang X, Li H, et al. Infectious SARS-CoV-2 in feces of patient with severe COVID-19. Emerg Infect Dis. 2020 May 18 [Epub ahead of print]. https:/ / doi.org/10.3201/eid2608.200681

6. Xiao F, Tang M, Zheng X, Liu Y, Li X, Shan H. Evidence for gastrointestinal infection of SARS-CoV-2. Gastroenterology. 2020;158:1831-1833.e3. https:// doi.org/10.1053/ j.gastro.2020.02.055

7. To KK-W, Tsang OT-Y, Yip CC-Y, Chan K-H, Wu T-C, Chan JM-C, et al. Consistent detection of 2019 novel coronavirus in saliva. Clin Infect Dis. 2020 Feb 12 [Epub ahead of print]. https://doi.org/10.1093/cid/ciaa149

8. Stadnytskyi V, Bax CE, Bax A, Anfinrud P. The airborne lifetime of small speech droplets and their potential importance in SARS-CoV-2 transmission. Proc Natl Acad Sci U S A. 2020 May 13 [Epub ahead of print]. https:/ / doi.org/10.1073/ pnas. 2006874117

Address for Correspondence: Eun Hwa Choi, Department of Pediatrics, Seoul National University Children's Hospital, 101 Daehak-ro, Jongno-gu, Seoul, 03080, South Korea; email: eunchoi@snu.ac.kr

\section{Coronavirus Disease Exposure and Spread from Nightclubs, South Korea}

\author{
Cho Ryok Kang, Jin Yong Lee, Yoojin Park, \\ In Sil Huh, Hyon Jeen Ham, Jin Kyeong Han, \\ Jung II Kim, Baeg Ju Na, Seoul Metropolitan \\ Government COVID-19 Rapid Response Team \\ (SCoRR Team)
}

\footnotetext{
Author affiliations: Seoul Metropolitan Government, Seoul, South Korea (C.R. Kang, H.J. Ham, J.K. Han, J.I. Kim, B.J. Na); Seoul National University Boramae Medical Centre, Seoul (J.Y. Lee); Seoul Centre for Infectious Disease Control and Prevention, Seoul (Y. Park, I.S. Huh)
}

DOI: https://doi.org/10.3201/eid2610.202573
At least 246 cases of coronavirus disease (COVID-19) have been linked to nightclubs in Seoul, South Korea. During the April 30-May 5 holiday, young adults from across the country who visited nightclubs in Seoul contracted COVID-19 and spread it nationally. Nightclubs were temporarily closed to limit COVID-19 spread.

South Korea had 10,801 confirmed cases of coronaVvirus disease (COVID-19) by May 4, 2020 (1). The epidemic curve of the cumulative number of cases had plateaued in April (Appendix Figure 1, https:/ / wwwnc.cdc.gov/EID/article/26/10/20-2573-App1. pdf). Nightclubs that had been closed as part of the social distancing policy reopened on April 30, ahead of the April 30-May 5 Golden Week holiday. People from around the country visited the Itaewon area (Itaewon-dong) in downtown Seoul during the holiday period. Itaewon is known for its diversity and contains a US Army base, multiple embassies, and several well-known nightclubs.

Starting on May 6, several COVID-19 cases were confirmed among persons who had visited nightclubs in Itaewon during the holiday. Secondary transmission by case-patients linked to the Itaewon nightclubs led to local transmission of COVID-19 in other parts of the country (Figure). On May 9, the Seoul Metropolitan Government announced indefinite closure of all nightclubs in Seoul to control the source of the outbreak. Subsequently, several regions prohibited mass gatherings.

The Seoul Metropolitan Government and Yongsan-gu Office, in cooperation with the Seoul Metropolitan Police Agency, conducted contact tracing of persons who had visited any of the 5 major nightclubs in Itaewon during April 30-May 6. The use of cell phone location data, credit card records, and lists of nightclub visitors led to the identification of 5,517 persons for screening; of those, 1,257 were actively monitored. An additional 57,536 persons who had spent $>30$ minutes in the vicinity of the nightclubs, as determined by their cell phone location data, were sent a series of text messages encouraging them to undergo testing.

After media outlets reported that venues at the epicenter of the outbreak were gay nightclubs, a rumor spread that this COVID-19 outbreak originated among gay men. Authorities became concerned that this rumor could adversely affect nightclub visitors' willingness to be tested. Because of prejudice against homosexuality, gay men in South Korea usually experience discrimination and stigmatization and so are often unwilling to reveal their sexual identity (2). Thus, the Seoul Metropolitan Government consulted sexual-minority groups to discuss ways to encourage 